\section{Augusto y el eco epigráfico de Munda en Carthago Nova, Saguntum y Tarraco}

\author{
Juan Manuel Abascal Palazón \\ Universidad de Alicante \\ juan.abascal@ua.es
}

\section{RESUMEN}

Carthago Nova y Saguntum fueron colonias pompeyanas que tras la victoria de César en Munda, el año 45 a.C., pasaron a la órbita política de César; en tiempos de Augusto, ambas ciudades desarrollaron programas epigráficos que guardan mucha relación entre sí y que son evidencia de su fidelidad a Augusto. La investigación moderna ha reconocido en Tarraco una deductio colonial con veteranos que pudieron haber estado en la batalla de Munda; uno de ellos pudo ser un magistrado conocido por un fragmento epigráfico. Así, Carthago Nova, Saguntum y Tarraco presentarían testimonios epigráficos augusteos que podrían considerarse el eco de la batalla de Munda.

Palabras clave: Hispania Citerior. Epigráfica romana. César. Augusto. Litterae aureae.

\section{Augustus and the Epigraphical Echo of Munda in Carthago Nova, Saguntum and Tarraco}

\begin{abstract}
Carthago Nova and Saguntum were Pompeian colonies that after César's victory in Munda 4 in 45 BC entered the political orbit of Caesar; in Augustean times, both cities developed epigraphic programs that have much relation to each other and that are evidence of his fidelity to Augustus. The modern research has admitted in Tarraco a colonial deductio with veterans that could have been in the battle of Munda; one of them could be a magistrate known by an epigraphic fragment. In this way, Carthago Nova, Saguntum and Tarraco would present epigraphic Augustan testimonies that might be considered the echo of the battle of Munda.
\end{abstract}

Key Words: Hispania Citerior. Roman Epigraphy. Caesar. Augustus. Litterae aureae. 
Según Nicolás de Damasco, ${ }^{1}$ el año 45 a.C. Octaviano partió de Italia hacia Hispania para reunirse con César, que obtuvo ese año la victoria en Munda contra los hijos de Pompeyo; al llegar a Tarragona, Octaviano supo que César ya no estaba allí y hubo de alcanzarle en el sur de Hispania, cerca de Calpia, según dice el texto. Luego, ambos emprendieron el viaje marítimo de regreso desde Gades a Tarraco y se detuvieron en Carthago Nova con el pretexto oficial de atender asuntos burocráticos y administrar justicia; ${ }^{2}$ allí permanecieron sólo algunos días, pues a comienzos del otoño de ese año Octaviano se encontraba ya en Roma, donde recibió del Senado el rango patricio. ${ }^{3}$ Dice Nicolás de Damasco ${ }^{4}$ que César y Octaviano se reunieron en Carthago Nova con aquellos que tenían interés en ver a César, entre los que se encontraban algunos que esperaban su recompensa por el apoyo que le habían prestado. Pero por el mismo Damasceno $^{5}$ sabemos que, durante esa estancia, Octaviano concedió audiencia a los saguntinos, que pretendían de César la retirada de unos cargos que no conocemos; Octaviano actuó como su portavoz y consiguió el perdón de César para ellos. El relato sobre la primera presencia del futuro emperador Augusto en la Península Ibérica ligó así de forma nítida la historia de Carthago Nova y Saguntum, dos ciudades unidas también por su pasado común en la segunda guerra púnica y por haber vinculado su futuro a la figura de Pompeyo Magno.

Hace algunos años tuve oportunidad de demostrar que el registro monetario y epigráfico de los IIviri quinquennales conocidos en Carthago Nova probaba que la concesión de los privilegios coloniales a la ciudad habría tenido lugar al menos en el año 54 a.C., si no antes si los magistrados de $R P C 146$ llegaron a ocupar sus funciones en un año censal; ${ }^{6}$ esa datación supone asegurar que la ciudad obtuvo el rango colonial durante la etapa del gobierno de Pompeyo en Hispania. Unos meses después de editarse mi propuesta, la relectura de algunas monedas de Saguntum, llevada a cabo por P. P. Ripollès y J. Velaza, demostró que esa ciudad tuvo un pasado colonial antes de convertirse en municipium; ${ }^{7}$ es más, si tenemos en cuenta que el año 56 a.C. la ciudad era una civitas foederata, ${ }^{8}$ que hacia 4-3 a.C. ya era un municipium latino ${ }^{9}$ y que la familia de los Fabios de la ciudad había recibido la ciudadanía de Pompeyo, ${ }^{10}$ todo apunta a que la colonia saguntina citada en las monedas recibió también su rango de manos de Pompeyo Magno, ${ }^{11}$ como había ocurrido con Carthago Nova. Los antece-

1 Nic. Dam., de vita Aug. 11.23-25; 12.26-27. Dio, 43.41 .3 confirma esta participación del futuro Augusto en las últimas campañas cesarianas. Este trabajo se ha realizado en el marco del proyecto de investigación HAR2012-32881 de la Secretaría de Estado de Investigación, Desarrollo e Innovación del Gobierno de España.

2 Nic. Dam., de vita Aug. 12.26. Empleo la edición de PARMEntier - BARone 2011.

3 Nic. Dam., de vita Aug. 15. Para la fecha, Kienast 1996, 61.

4 Nic. Dam., de vita Aug. 12. KIENAST 1996, 4.

5 Nic. Dam., de vita Aug. 12.

6 Una exposición detallada de esta cuestión en Abascal 2002.

7 Ripollès - Velaza 2002, 285-291. Las leyendas son las siguientes: L. AEM[---]AE AED COL; CN BAEBI GLAB L CALPVRN AED C S; [-] BAEB GLOB M POP RV[-]. [a]E[d col]. Cf. también RIPOLLÈS LLORENS 2002, 203-204.

8 Cic., Balb. 23.

9 Alföldy en $C I L \mathrm{II}^{2} / 14,305$.

10 Cic., Balb. 51.

11 Esta es la tesis, plenamente justificada, de RIPOLLÈs - VelAZA 2002, 288-289. 
dentes pompeyanos de ambas ciudades, unidas en su día por su estatuto colonial de época pompeyana, pasarían factura a ambas tras la victoria cesariana en la batalla de Munda.

Con los datos que hoy conocemos sobre la primitiva historia de ambas ciudades es más fácil entender el relato de Nicolás de Damasco: hay que suponer que la estancia de César y Octaviano en Carthago Nova el año 45 a.C. pretendía asegurar el cambio de rumbo político de esta vieja colonia pompeyana, ${ }^{12}$ asegurar su fidelidad a la causa cesariana y tranquilizar a las élites que venían explotando desde hacía más de un siglo sus ricas minas de plata. Por lo que respecta a Saguntum, tras los ecos de la victoria de Munda, sus habitantes enviaron una legación para entrevistarse con César en Carthago Nova y consiguieron la mediación de Octaviano ${ }^{13}$ las razones de esa embajada parecen obvias: Saguntum afrontaba las mismas represalias que pudieran corresponder a Carthago Nova como parte de los apoyos pompeyanos y prefirió tomar la iniciativa para evitar el escarnio de una escala en su puerto del vencedor de Munda, que sin duda era sabedor de que la costa mediterránea peninsular era por entonces parte del gran feudo pompeyano. ${ }^{14} \mathrm{Sin}$ duda alguna, para la élite saguntina debió de ser menos doloso someterse a la voluntad de César en Carthago Nova que escenificar esa sumisión ante sus propios conciudadanos.

¿Qué ocurrió en Carthago Nova y Saguntum después del año 45 a.C.? Carecemos de noticias históricas bien fechadas en ambos enclaves pero sabemos que las dos ciudades dieron muestras reiteradas e insistentes de su fidelidad al emperador Augusto y a su círculo inmediato, básicamente mediante el hábito epigráfico. No en vano los saguntinos se habían convertido prácticamente en clientes de Augusto cuando solicitaron su mediación el año 45 a.C. y los de Carthago Nova habían preservado sus privilegios durante aquella visita. Ambas ciudades tenían motivos sobrados para ser leales a Augusto y llevaron a cabo programas epigráficos que están íntimamente ligados con los que se desarrollaron en la propia Roma.

Esos ecos directos se evidencian, en primer lugar, en el hecho de que Carthago Nova y Saguntum son por ahora las dos únicas ciudades de la costa mediterránea de Hispania en las que tenemos evidencia de inscripciones formadas con litterae aureae en los pavimentos de sus respectivos foros. ${ }^{15}$ De la primera ciudad conservamos sendos fragmentos de dos losas que formaron parte de la inscripción del suelo del foro; en una de ellas se lee lo que parece una parte del cognomen Celer ${ }^{16}$ y en la otra sólo

12 Probablemente fue durante este viaje del año 45 a.C. cuando la colonia pompeyana de Carthago Nova asumió el sobrenombre de Iulia con que aparecerá más tarde en las monedas, y al igual que otras ciudades de filiación cesariana pasaría a ser denominada $u r b s$, adquiriendo el título oficial de colonia Urbs Iulia Carthago Nova.

13 Nic. Dam., de vita Aug. 12.

14 Amela 2000, 7-33 y 2001, 93-122. La intermediación ante César proporcionaría a Augusto una relación directa con la élite local; cf. al respecto ALFÖLDY 1984, 193-238.

15 Sobre las inscripciones de este tipo cf. especialmente ALFÖLDY 1991, 289-324, especialmente 297-299; ALFÖLDY 1990, 21-27; ID. 1992, 231-248; ID. 1995, 205 ss; ID. 1997 (con las traducciones que se especifican en la bibliografía final), 4-8 y 26-31; AbASCAL - AlFöldy - Cebrián 2001, 117-130; AbASCAL - Alföldy 2002, 80-98; Noguera - ABASCAl 2003, 11-63; AlFÖLdy 2012, 429-454.

16 ABASCAL - Noguera - MAdrid 2012, 291-294. 
[---] Ap [---] (Figura 1). ${ }^{17}$ Más significativa es la inscripción pavimental del foro de Saguntum (Figura 2), ${ }^{18}$ financiada por la gens Baebia local.
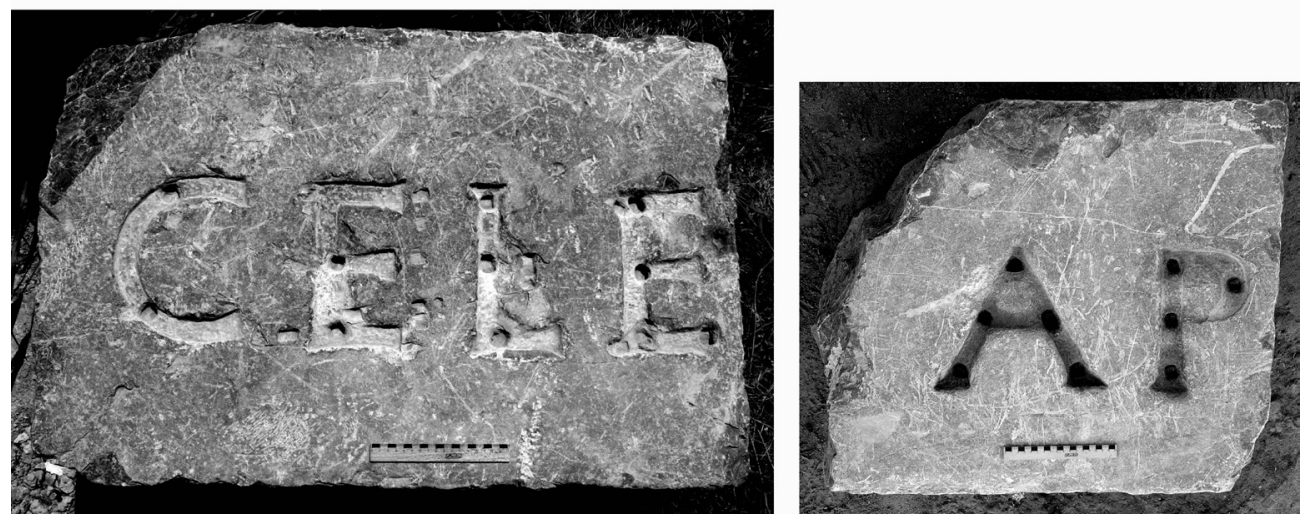

Fig. 1. Testimonios de la inscripción pavimental del foro de Carthago Nova (J. M. Abascal).

Este tipo de inscripciones, que mostraban la riqueza y el rango de quienes las financiaban, constituían evidencias de proximidad con la práctica epigráfica de la propia Roma, donde el ejemplo más antiguo sigue siendo la inscripción original del obelisco colocado delante de la Basílica de San Pedro, que fue dedicado en Alejandría por C. Cornelius Gallus entre agosto y octubre del año 30 a.C. ${ }^{19}$ Esta técnica de escritura epigráfica se desarrolló especialmente a partir del año 17 a.C. que fue, según la ideología del principado augusteo, el año del nacimiento de la nueva aurea aetas. Ello explicaría el rápido desarrollo que alcanzó desde ese momento en las provincias, en donde el mismo año 16 a.C. se construyeron las inscripciones de la puerta augustea de la colonia de Nemausus (Nîmes) ${ }^{20}$ y las inscripciones del teatro de Augusta Emerita, inaugurado ese mismo año. ${ }^{21}$ La tradición de colocar este tipo de inscripciones en los foros se encuentra ya en el foro de Ferentinum, en torno al año 30 a.C., ${ }^{22}$ y volverá a reconocerse en la pavimentación del foro de Roma llevada a cabo por el pretor L. Naevius Surdinus hacia el 12 a.C. ${ }^{23}$ en el forum vetus de Lepcis Magna del año 4 o 5 d.C. ${ }^{24}$ o en la inscripción del foro de Hippo Regius de 77/78 d.C. ${ }^{25}$ Los

17 Noguera - Abascal 2003, 53-68.

18 AlföLdy 1977, 7-13 y 43-49; ID. en CIL II²/14, 374, con el resto de la bibliografía: Cn(aeus) Baebius Cn(aei) f(ilius) G[al(eria) Ge]min[u]s testam[ento] foru[m de sua pecun]ia d[onavit Cn(aeus) Baebius Cn(aei) f(ilius) Gal(eria) ---]ni[nus?] fra[ter heres dedicavit]. La inscripción debió tener originalmente la impresionante longitud de unos 40 metros.

19 ALFÖLDY 1990, 21-27, con la bibliografía anterior; sobre la fecha de la inscripción ibid. 33-37.

20 CIL XII, 3151.

21 CIL II, 474 = ILS 130; MÉlida 1925, 142 ss; Stefano MANZElla 1987, 182.

22 En torno a esa fecha hay que situar también la inscripción del foro de Ferentinum (CIL I2, $1527=C I L$ X, 5847 = ILLRP 587; ALFÖLDY 1990, 70, con más bibliografía).

23 CIL VI, 37068; cf. AlfÖldy en CIL VI.8.3, p. 4.814 con bibliografía.

24 Di ViTA-ÉVRARD 1990, 315-331.

$25 A E 1949,46$ y 1955, p. 147. 
testimonios pavimentales en Hispania son los foros de de Segobriga, Ituci (Torreparedones, Baena, Córdoba), ${ }^{26}$ Carthago Nova y Saguntum, así como la orchestra del teatro de Italica. ${ }^{27}$ Todos estos ejemplos son de época augustea y al menos coetáneos o posteriores al tercer y último viaje de Augusto a Hispania en 15-13 a.C. ${ }^{28}$

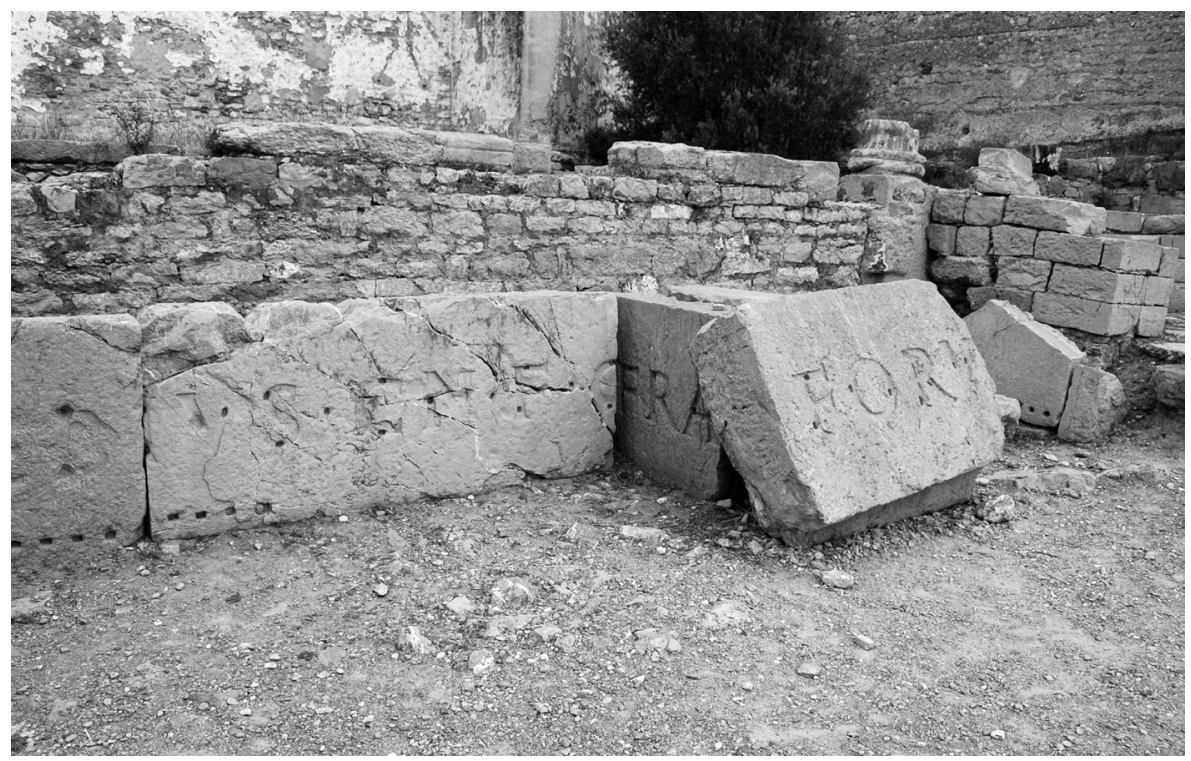

Fig. 2. Bloques con inscripción del suelo del foro de Saguntum (J. M. Abascal).

Mediante el empleo de esta técnica en sus inscripciones pavimentales, Carthago Nova y Saguntum podían mostrar espacios forenses muy próximos en su estética a los de las ciudades itálicas y de la propia Roma y sus élites podían manifestar públicamente su mecenazgo cívico y con ello justificar su rango social. Esta mimetización de las costumbres epigráficas de la Urbe puede leerse también en términos de fidelidad dinástica, especialmente si tenemos en cuenta que fue acompañada — tanto en Carthago Nova como en Saguntum - de un programa epigráfico para soportes de estatuas que ligaba la historia de ambas ciudades a la familia de Augusto y a su círculo político.

Esas inscripciones nos enseñan que en Carthago Nova se honró como patronos a Agripa ${ }^{29}$ al joven Tiberio (seguramente entre la muerte de Agripa y el exilio de Rodas, es decir, 12 a.C. -6 a.C.), ${ }^{30}$ a P. Silius Nerva, cónsul ordinario del año 20 a.C.

26 Morena et ali 2011, 157-159; Ventura ET aLII 2013, 236-238; Ventura 2014, 73-74; Ventura MORENA, en prensa.

27 Blanco Freijeiro 1977, 134-139; Luzón 1978, 272 (AE 1978, 402); GonzÁLez Fernández 1991 (= CILA Sevilla), $\mathrm{n}^{\circ} 383$, con más bibliografía.

28 Sobre los viajes de Augusto a la Península Ibérica, cf. ABASCAL 2006 [2009], 63-78.

29 Косн 1979, 205-214, Taf. 5 (AE 1979, 366), con la bibliografía anterior. AbasCal - Ramallo 1997, $\mathrm{n}^{\circ} 42$.

30 CIL II, supp. 5930 (ILS 144). AbasCal - Ramallo 1997, $\mathrm{n}^{\circ} 41$ con el resto de la bibliografía. 
y gobernador de la Citerior entre 19 y 16 a.C. ${ }^{31}$ y al rey Iuba II de Mauretania circa 3-4 a.C. ${ }^{32}$ A ello hay que añadir un altar dedicado en el teatro entre los años 5 a.C. y 1 d.C. que hace referencia a Caius Caesar ${ }^{33}$ y el hecho de que los dos dinteles de acceso al proscaenium contuvieran sendas dedicaciones a los césares Caius y Lucius. ${ }^{34} \mathrm{La}$ existencia de estos programas epigráficos en honor de Augusto y los jóvenes césares es un fenómeno bien documentado en Hispania, ${ }^{35}$ aunque no con tanta intensidad. No obstante, debe tenerse en cuenta que a partir del año 12 a.C. cobraron fuerza las dedicaciones a los dos césares, convertidos por la muerte de su padre en herederos virtuales de Augusto. Este programa epigráfico - tan temprano y tan centrado en Augusto y en su entorno inmediato - supera con creces a los conocidos en otras ciudades de Hispania, incluidas las capitales provinciales, y sólo es parangonable con lo que conocemos en el municipio bético de Ulia (Montemayor, Córdoba, conventus Astigitanus) y en Urgavo (Arjona, Jaén, conventus Cordubensis). En Ulia se colocaron entre los años 12 a.C. y 4 d.C. cinco pedestales en honor de Caius Caesar, ${ }^{36}$ Lucius Caesar, ${ }^{37}$ Agrippa ${ }^{38}$ Agrippa Postumus, ${ }^{39}$ y el joven Tiberio César. ${ }^{40}$ De Urgavo procede una dedicación a Augusto del año 6 a.C., ${ }^{41}$ otra fechada entre los años 11 y 12 d.C., ${ }^{42}$ dos dedicaciones a Lucius Caesar, ${ }^{43}$ y otra para Livia como Iulia Augusta erigida entre los años 14 y 29 d.C. ${ }^{44}$

Esos mismos vínculos augusteos — que perdurarán en época tiberiana- se perciben en Saguntum, que entre los años 4 y 3 a.C. erigió estatuas con sus correspondientes pedestales epigráficos para el propio Augusto y para Caius Caesar, ${ }^{45}$ el mismo año 14 d.C. para Tiberio, ${ }^{46}$ entre 18 y 19 d.C. para Germánico y Druso, ${ }^{47}$ y entre 23 y 30 d.C. para Druso el hijo de Germánico. ${ }^{48}$ Poco después del año 14 d.C. también se honraría como patrono al senador Paullus Aemilius Regillus. ${ }^{49}$ Atrás habían quedado ya las décadas turbulentas del estertor republicano y la necesaria pero involuntaria implicación de algunas ciudades hispanas en la guerra civil. La ciudad de Saguntum, convertida ya $\mathrm{n}^{\circ} 45$.

31 Syme 1989, 417; AlfÖLdy 1969, 7; PIR III, S-512. Sobre la inscripción, cf. AbaSCAL - Ramallo 1997,

32 CIL II, 3417 + p. 711 y 952; ABASCAL - RAMALLO 1997, n 49. Iuba II ejerció magistraturas honoríficas in absentia sobre determinadas ciudades hispanas. Aparentemente, Carthago Nova no recurrió al patronato urbano hasta bien entrada la época augustea, y si lo hizo fue probablemente porque sólo entonces había de ser una herramienta necesaria para el pleno desarrollo de la ciudad.

33 AE 1992, 1076; Abascal - Ramallo 1997, nº13.

34 AE 1992, 1075; Abascal - Ramallo 1997, nº14 y 15.

35 Abascal 1996, 45-82; Boschung 1990, 391-400.

36 CIL II $^{2} / 5,486$ (= II 1525).

37 CIL II $2 / 5,487$ (= II 1526).

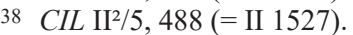

$39 C$ IL II $2 / 5,489$ (= II 1528).

$40 C_{\text {CIL II }}^{2} / 5,490$ (= II 1529).

$41 C I L \mathrm{II}^{2} / 7,70$ (= II 2107).

$42 C I L \mathrm{II}^{2} / 7,69$ (= II 2106).

$43 C I L \mathrm{II}^{2} / 7,71$ y 72 (= II 2109-2110).

$44 \mathrm{CIL} \mathrm{III}^{2} / 7,73$ (= II 2108).

45 Alföldy, CIL II²/14, 305 (= II 3827. Augusto) y CIL II²/14, 306 (= II 3828. Caius Caesar).

46 ALFÖLDY, CIL II ${ }^{2} / 14,307$.

47 Alföldy, CIL II²/14, 308 (Germánico) y CIL II²/14, 309 (= II 3829. Druso).

48 Alföldy, CIL II ${ }^{2} / 14,310$.

49 Alföldy, CIL II²/14, 329 (= II 3837). 
en municipio, y Carthago Nova, aún con su viejo estatuto colonial, afrontarían el comienzo del Principado bajo las mismas reglas que decenas de ciudades en otros puntos del Mediterráneo pero con una especial vocación de fidelidad.

Ninguna otra ciudad de la fachada mediterránea, ni siquiera Tarraco, ha proporcionado programas epigráficos oficiales de época augustea tan ricos como estos. Tarraco como capital provincial y Carthago Nova y Saguntum por su papel histórico fueron las ciudades de la fachada mediterránea de Hispania de mayor vinculación con Roma pero Carthago Nova y Saguntum fueron las dos únicas en que se desarrollaron esos programas epigráficos augusteos y en que se construyeron inscripciones con litterae aureae en los pavimentos forenses. ${ }^{50}$ ¿Una causalidad?, ¿un espejismo histórico derivado del estado de la investigación? El tiempo contestará a esas preguntas pero, hoy por hoy, todo parece indicar que las dos antiguas colonias pompeyanas, sacudidas políticamente por la victoria de César en Munda, llegaron a ser en tiempos augusteos sendos altavoces de la política imperial que convirtieron sus foros urbanos en galerías epigráficas en honor de Augusto, de su familia y de su entorno político, y que emplearon para ello las mismas técnicas que en esos años se estaban usando en Roma. Como ejemplos de mimetismo epigráfico estos dos testimonios son casi únicos.

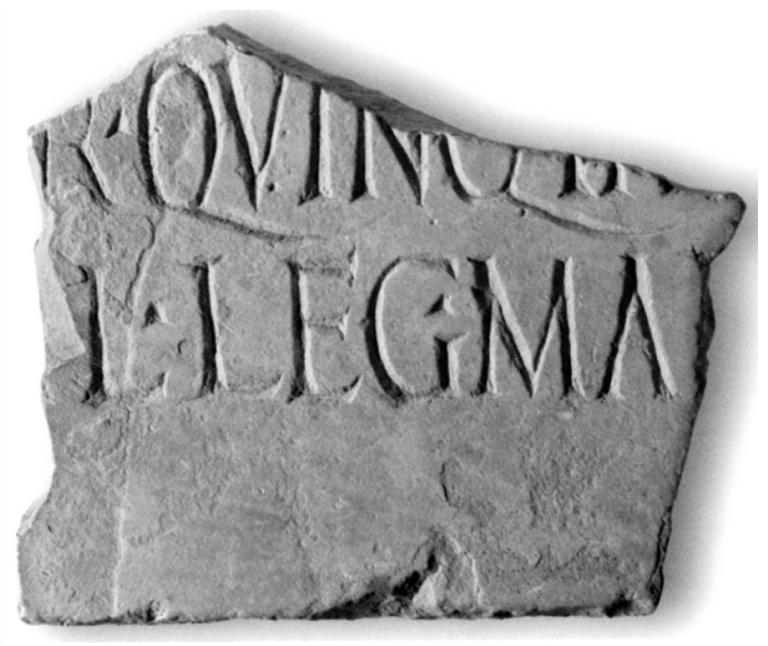

Fig. 3. Testimonio epigráfico de la legio Martia en Tarraco (según Ruiz de Arbulo).

50 En lo que no existe relación alguna entre ambos centros es en la técnica empleada para la construcción de pedestales ecuestres, que en Carthago Nova revela el uso de los llamados pedestales compuestos, formados por bloques anepígrafos de diferentes proporciones que están colocados detrás del bloque con la inscripción, de modo que entre todos suman el volumen completo de un pedestal. Esta técnica está ahora muy bien documentada en Segobriga para los pedestales dedicados a C. Calvisius Sabinus, legatus (Augusti) pro praetore de la Hispania Citerior (AE 2003, 981), a M. Licinius Crassus Frugi (AE 2003, 982) o al escriba augusteo M. Porcius M.f. Pup. (AE 2003, 986). El pedestal compuesto podía llegar a tener hasta 6/7 paralelepípedos en su parte media, un número indeterminado de ellos en el zócalo y generalmente dos piezas en el coronamiento. Sobre los pedestales ecuestres, vid. en general, BERGEMANN 1990, 119; cf. los comentarios al respecto de ZeLAZOWWSKI 2001, 133-134. Sobre pedestales ecuestres monolíticos y compuestos en Hispania, cf. ALFÖLDY - Abascal - Cebrián 2003, 255-274; Abascal - Cebrián - Trunk 2004, 219-256; Stylow 2008, 1051 1062. Sobre los pedestales compuestos de Carthago Nova, vid. Abascal 2009, 103-113. 
Hasta aquí hemos hablado sólo del eco epigráfico de Munda en la vida de Carthago Nova y Saguntum. Pero tenemos evidencias de que eso eco pudo alcanzar también a la propia Tarraco. ${ }^{51}$ Un fragmento de placa de caliza descubierto en 1980 en el solar del teatro de Tarraco (Figura 3) presenta el siguiente texto: ${ }^{52}$

$$
\begin{aligned}
& \text { [--- IIvi]r quinq(uennalis) II +[---] } \\
& \text { [---? trib(unus) m] il(itum) leg(ionis) Mar[tiae ---?] }
\end{aligned}
$$

Según J. Ruiz de Arbulo ${ }^{53}$ y G. Alföldy, ${ }^{54}$ que se ocuparon por separado y en ese orden del estudio de la placa, el anónimo personaje citado en el texto fue tribuno militar de la legio Martia, una unidad sólo documentada entre los años 46 y 42 a.C., ${ }^{55}$ y después se trasladó a Tarraco, en donde desempeñó al menos en dos ocasiones el duunvirado quinquenal. La referencia a la legio Martia conviene bien a la cronología del documento que, por la forma de las letras y el tipo de las interpunciones, debe fecharse a inicios del Principado, por lo que el tribunado legionario que se cita debió desempeñarse a finales de la República. Es decir, el magistrado citado en el texto es a fecha de hoy el más antiguo de los magistrados de Tarraco conocido por las inscripciones y no habría inconveniente en considerar que este tribuno fue uno de los veteranos legionarios que llegó a Tarraco en el momento de la deductio colonial a finales de la época cesariana. ${ }^{56}$ Pero si la legio Martia fue - como parece probableuna parte de los efectivos de que dispuso César en la batalla de Munda el 17 de marzo del año 45 a.C., ${ }^{57}$ entonces el anónimo tribuno militar y luego magistrado de Tarraco sería uno de los veteranos trasladados a la capital de la Citerior después de la victoria cesariana, ${ }^{58}$ lo que no debería extrañarnos pues sabemos por Livio $(34.9)^{59}$ que otro contingente de veteranos de Munda fue instalado en Emporion.

De esta manera, en las semanas inmediatamente posteriores a la victoria de Mun$d a$, César habría recibido pruebas de lealtad de las antiguas colonias pompeyanas de Carthago Nova y Saguntum, y poco después algunos de sus veteranos serían asentados en Emporion y probablemente también en Tarraco, donde uno de los tribunos que formaban parte de la deductio pudo llegar a desempeñar en dos ocasiones el cargo de duunviro quinquenal.

Las emisiones monetarias de Carthago Nova y Saguntum son nuestras mejores evidencias de su pasado pompeyano y permiten explicar el pasaje de Nicolás de Da-

51 En la amplísima bibliografía sobre la ciudad conviene entresacar las siguientes obras: ALFÖLDY 1978/1991; Ruiz de Arbulo 1992, 115-130; Alföldy 2004, 7-155; RuIZ de Arbulo 2009, 36-55; Mar Ruiz DE ARBulo 2010, 207-538.

52 AlföLDY en CIL II ${ }^{2} / 14,1023$.

53 Ruiz de Arbulo 2009, 37-39 y 48-53.

54 AlFöldy en CIL II ${ }^{2} / 14,1023$.

55 Ruiz de Arbulo 2009, 39. La unidad aparece citada con frecuencia en las fuentes antiguas: Cic., Phil. 3.6-7 y $39 ; 4.5-6 ; 5.4 ; 5.23 ; 5.28 ; 5.46 ; 5.53 ; 10.21 ; 11.20 ; 12.8 ; 12.29 ; 14.26-27 ; 14.31-33 ; 14.36-38$; Vell., 2.61.2; Dio, 45.13.3. Cf. Ruiz de Arbulo 2009, 39-48.

56 Tal es la conclusión de RuIZ DE Arbulo 2009, 54 y G. AlfÖLdy en CIL II²/ 14, 1023.

57 Keppie 1991, 118: Ruiz de Arbulo 2009, 39.

58 Hipótesis formulada por RUIZ DE ARBULO 2009, 50-51.

59 Sobre el particular, cf. RuIz de ARBULo 2009, 52, con más bibliografía. 
masco referido a la estancia de César y Octaviano en Carthago Nova, las inscripciones de tiempos augusteos prueban la lealtad de ambas ciudades al primer emperador y un pequeño fragmento de placa de Tarraco ayuda a intuir la primera etapa de la deductio colonial de la capital provincial. Todas estas evidencias, que por separado son muy difíciles de entender y explicar, en conjunto constituyen ecos de un mismo acontecimiento histórico desarrollado en las campiñas béticas en marzo del año 45 a.C. y que tendría lectura epigráfica varias décadas después.

\section{BibLIOGRAFÍA}

Abascal, J. M.

(1996): "Programas epigráficos augusteos en Hispania", Anales de Arqueología Cordobesa 7, 45-82.

(2002): "La fecha de la promoción colonial de Carthago Nova y sus repercusiones edilicias", Mastia 1, 21-44.

(2006): "Los tres viajes de Augusto a Hispania y su relación con la promoción jurídica de las ciudades", Iberia 9, 63-78.

(2009): "Pedestal ecuestre para C. Laetilius M. f. en Carthago Nova (Hispania citerior)", Mastia 8, 103-113.

Abascal, J. M. - AlföLdy, G. (eds.) (2002): El Arco romano de Medinaceli (Soria, Hispania citerior), Madrid.

Abascal, J. M. - Alföldy, G. - Cebrián, R. (2001): "La inscripción con letras de bronce y otros documentos epigráficos del foro de Segobriga", AEspA 74, 117-130.

Abascal, J. M. - Cebrián, R. - TrunK, M. (2004): "Epigrafía, arquitectura y decoración arquitectónica del foro de Segobriga", [en] S. F. Ramallo (ed.), La decoración arquitectónica en las ciudades romanas de Occidente. Actas del Congreso Internacional celebrado en Cartagena entre los días 8 y 10 de octubre de 2003, Murcia, 219-256.

Abascal, J. M. - Noguera, J. M. - Madrid, Mª J. (2012): "Nuevas inscripciones romanas de Carthago Nova (Cartagena, Hispania Citerior)", ZPE 182, 287-290.

Abascal, J. M. - Ramallo, S. (1997): La ciudad de Carthago Noua III. La documentación epigráfica, Murcia.

ALFöLDY, G.

(1969): Fasti Hispanienses. Fasti Hispanienses. Senatorische Reichsbeamte und Offiziere in den spanischen Provinzen des römischen Reiches von Augustus bis Diokletian, Wiesbaden.

(1977): Los Baebii de Saguntum, Valencia.

(1978/1991): "Tarraco", RE, suppl. 15, 1978, col. 569-643 (ed. castellana: Tarraco [Forum, Temes d'història i d'arqueologia tarragonines 8], Tarragona 1991).

(1984): "Drei städtische Eliten im römischen Hispanien”, Gerión 2, 193-238.

(1990): Der Obelisk auf dem Petersplatz in Rom. Ein historisches Monument der Antike (Sitz.-Ber. d. Heidelberger Akad. d. Wiss., Phil.-hist. Kl., Jg. 1990, Bericht 2), Heidelberg. (1991): "Augustus und die Inschriften: Tradition und Innovation. Die Geburt der imperialen Epigraphik", Gymnasium 98, 289-324 (="Augusto e le iscrizioni: tradizione ed innovazione. La nascità dell'epigrafia imperiale", Scienze dell'Antichità. Storia, Archeologia, Antro- 
pologia. Dipartimento di Scienze Storiche, Archeologiche, Antropologiche dell'Antichità. Università degli di Studi di Roma "La Sapienza” 5, 1991 [1994], 573-600).

(1992): "Die Inschrift des Aquäduktes von Segovia. Ein Vorbericht", ZPE 94, 231-248.

(1995): "Eine Bauinschrift aus dem Colosseum", ZPE 109, 195-226.

(1997): Die Bauinschriften des Aquäduktes von Segovia und des Amphitheaters von Tarraco. Mit einem Anhang von Peter Witte (=Madrider Forschungen 19), Berlin - New York. (=La inscripción del acueducto de Segovia, Madrid 2010; Las inscripciones monumentales del anfiteatro de Tarraco, Tarragona 2012).

(2004): "Introducción histórica", [en] X. Dupré (ed.), Las capitales provinciales de Hispania 3. Tarragona, Colonia Iulia Urbs Triumphalis Tarraco, Roma, 7-155.

(2012): "El acueducto de Segovia y su inscripción: dos decenios después de la "aventura epigráfica", $\operatorname{MDAI}(M)$ 53, 429-454.

Alföldy, G. - Abascal, J. M. - Cebrián, R. (2003): “Nuevos documentos epigráficos del foro de Segobriga. Parte primera: inscripciones votivas, imperiales y de empleados del Estado romano", ZPE 143, 255-274.

Amela, L.

(2000): “Colonias y municipios cesarianos de la provincia Hispania citerior", Anuari de Filologia. Studia Graeca et Latina 22/10, 7-33.

(2001): "Pompeyo Magno y el gobierno de Hispania en los años 55-50 a.C.", Hispania Antiqua 25, 93-122.

Bergemann, J. (1990): Römische Reiterstatuen. Ehrendenkmäler im öffentlichen Bereich, Mainz.

Blanco Freijeiro, A. (1977): "Epigrafía en torno al acueducto de Segovia, en Segovia", [en] Symposium de arqueología romana, Barcelona, 131-146.

Boschung, D. (1990): "Die Präsenz des Kaiserhauses im öffentlichen Bereich”, [en] W. Trillmich - P. Zanker (eds.), Stadtbild und Ideologie. Die Monumentalisierung hispanischer Städte zwischen Republik und Kaiserzeit. Madrid 1987, München, 391-400.

Di ViTA-Évrard, G. (1990): “IRT 520, le proconsulat de Cn. Calpurnius Piso et l'insertion de Lepcis Magna dans la provincia Africa", [en] L'Afrique dans l'Occident romain (Ier siècle av. J.C. - IVe siècle ap. J.C.), Roma, 315-331.

González Fernández, J. (1991): Corpus de inscripciones latinas de Andalucía, vol. II.2: Sevilla. La Vega (Italica), Sevilla.

KeppIE, L. (1991): “A centurion of legio Martia at Padova?”, Journal of Roman Military Equipment Studies 2, 115-121.

KIENAST, D. (1996): Römische Kaisertabelle. Grundzüge einer römischen Kaiserchronologie, $2^{\mathrm{a}}$ ed, Darmstadt.

Koсн, M. (1979): “M. Agrippa und Neukarthago”, Chiron 9, 205-214.

LuZÓN, J. Ma (1978): “Die neuattischen Rundaren aus Italica”, MDAI(M) 19, 272-289.

Mar, R. - Ruiz de Arbulo, J. (2010): “Tarragona romana: República i Alt Imperi (anys 218 a.C. - 265 d.C.)", [en] Historia de Tarragona, Tarragona, 207-538.

Mélida, J. R. (1925): Catálogo monumental, Provincia de Badajoz, Madrid.

Morena, J. A. - Ventura, A. - Márquez, C. - Moreno, A. (2011): "El foro de la ciudad romana de Torreparedones (Baena, Córdoba): primeros resultados de la investigación arqueológica (campaña 2009-2010)”, Italica 1, 141-165. 
Noguera, J. M. - Abascal, J. M. (2003): "Fragmentos de epígrafes e inscripción con litterae aureae del foro y del Augusteum de Carthago Nova", Mastia 2, 11-63.

Parmentier, E. - Barone, F. P. (2011): Nicolas de Damas. Histoires, Recueil de coutumes, Vie d'Auguste, Autobiographie, Paris.

Ripollès, P. P. - LloRens, Ma M. (2002): Arse-Saguntum. Historia monetaria de la ciudad y su territorio, Sagunto.

Ripollès, P. P. - VelazA, J. (2002): “Saguntum, colonia latina”, ZPE 141, 285-291.

Ruiz de Arbulo, J.

(1992): "Tarraco, Carthago Nova y el problema de la capitalidad en la Hispania citerior republicana", [en] Miscel.lània arqueològica a Josep M. Recasens, Tarragona, 115-130.

(2009): "La legio Martia y la fundació de la colonia Tarraco", [en] F. Tarrats (ed.), Tarraco pedra a pedra. Exposició Museu Nacional Arqueològic de Tarragona, 10 de juny al 22 de novembre de 2009, Tarragona, 36-55.

Stefano Manzella, I. DI (1987): Mestiere di epigrafista. Guida alla schedatura del materiale epigrafico lapidario (Vetera 1 ), Roma.

Stylow, A. U. (2008): “Ein neuer Statthalter der Baetica und frühe Reiterstatuenpostamente in Hispanien", [en] M. L. Caldelli - G. L. Gregori - S. Orlandi (eds.), Epigrafia 2006. Atti della XIVe rencontre sur l'épigraphie in onore di Silvio Panciera con altri contributi di colleghi, allievi e collaboratori (Tituli 9), Roma, 1051-1062.

Syme, R. (1989): La revolución romana, Madrid.

Ventura, Á. (2014): "El foro", [en] C. Márquez et alii (eds.), Torreparedones. Investigaciones arqueológicas (2006-2012), Baena, 69-86.

Ventura, Á. - Morena, J. A. en prensa: "Una arquitectura definida: la inscripción pavimental con litterae aureae y el foro de la colonia bética Virtus Iulia Ituci (Torreparedones, Baena, provincia de Córdoba)", [en] Actes du Colloque: Dire l'Architecture dans l'Antiquité (IRAA-CNRS, 18-19 nov. 2009), Aix-en-Provence.

Ventura, Á. - Morena, J. A. - Moreno, A. (2013): "La curia y el foro de la colonia Virtus Iulia Ituci", [en] B. Soler et alii (eds.), Las sedes de los ordines decurionum en Hispania. Análisis arquitectónico y modelo tipológico (=Anejos de AEspA 67), Madrid, 231-245.

Zelazowski, J. (2001): Honos bigae. Le statue onorarie romane su biga, Varsovia. 